\title{
Different Effects of Maternal Low-Isoflavone Soy Protein and Genistein Consumption on Hepatic Lipid Metabolism of 21-Day-Old Male Rat Offspring
}

\author{
Anna Han ${ }^{1,+} \ddagger$, Sae Bom Won ${ }^{1,2, \ddagger}$ and Young Hye Kwon ${ }^{1,2, *}$ \\ 1 Department of Food and Nutrition, Seoul National University, Seoul 08826, Korea; \\ anteanna@naver.com (A.H.); newspring@snu.ac.kr (S.B.W.) \\ 2 Research Institute of Human Ecology, Seoul National University, Seoul 08826, Korea \\ * Correspondence: hye0414@snu.ac.kr; Tel.: +82-2-880-6833 \\ + Current address: Department of Cancer Biology, Thomas Jefferson University, Philadelphia, PA 19107, USA. \\ $\ddagger$ These authors contributed equally to this work.
}

Received: 3 August 2017; Accepted: 18 September 2017; Published: 20 September 2017

\begin{abstract}
Amino acid composition and isoflavone are alleged contributors to the beneficial effects of soy protein isolate (SPI) on lipid metabolism. Therefore, we investigated the contributing component(s) of SPI in a maternal diet to the regulation of lipid metabolism in offspring. We also determined serum parameters in dams to investigate specific maternal cues that might be responsible for this regulation. Female rats were fed either a casein (CAS), a low-isoflavone SPI, or a casein plus genistein (GEN, $250 \mathrm{mg} / \mathrm{kg}$ ) diet for two weeks before mating, as well as during pregnancy and lactation. Male offspring (CAS, SPI and GEN groups) were studied 21 days after birth. The SPI group had lower serum triglyceride levels than the other groups. Serum cholesterol was reduced in both the SPI and GEN groups compared with the CAS group. Expressions of target genes of peroxisome proliferator-activated receptor $\alpha$ were altered in the SPI group. Serum aromatic amino acid levels in dams were associated with serum triglyceride in offspring. In conclusion, the maternal consumption of a low-isoflavone SPI diet or a casein diet containing genistein has different effects on the lipid metabolism of their offspring; however, more profound effects were observed in the SPI group. Therefore, the altered lipid metabolism of offspring may be attributed to amino acid composition in maternal dietary protein sources.
\end{abstract}

Keywords: amino acid; lipid metabolism; maternal diet; offspring liver; PPAR $\alpha$; soy protein isolate

\section{Introduction}

Several studies in humans and experimental animals have demonstrated that the early life environments may alter overall homeostatic regulatory mechanisms, thereby playing a critical role in influencing the susceptibility of offspring to the later development of certain diseases, as well as fetal programming [1]. Especially, nutrition during fetal and neonatal periods is one of the major environmental factors that affect the risk of chronic diseases such as obesity, hypertension, cardiovascular diseases, and diabetes in adulthood [2,3].

It has been shown that the consumption of a soy protein diet reduces serum triglyceride and cholesterol in rats $[4,5]$. In particular, soy isoflavone has been shown to alleviate metabolic diseases by reducing serum and hepatic lipid levels [6]. Similarly, exposure to dietary soy protein isolate (SPI) with isoflavone throughout the in utero, neonatal, and adult periods reduced hepatosteatosis compared with casein [7]. Although the maternal consumption of genistein or daidzein during pregnancy and lactation was reported to reduce the width to length ratio of myocytes, which may be related to the cardioprotective effects on their offspring during adulthood [8], most previous studies have investigated only the effect of supplementary genistein in a casein-based diet. 
Conversely, another study showed that body weight and fat pad weight between the offspring of dams placed on a soy protein diet (with isoflavone) and the offspring of dams placed on a casein plus genistein diet were different in spite of similar serum genistein levels in dams [9]. Similarly, dietary soy protein with low isoflavone reduced plasma and hepatic cholesterol and/or triglyceride in rats $[10,11]$. These results suggest that other SPI-derived dietary components may also play important roles in ameliorating metabolic diseases. Indeed, soy protein has a different amino acid composition than casein, with higher amounts of several amino acids, including cysteine, arginine, and glycine, and lower amounts of methionine. It is reported that the effect of dietary soy protein on lipid metabolism may be mediated by its low proportion of methionine among the total sulfur-containing amino acids [12]. Glycine has also been shown to stimulate insulin secretion [13], suggesting that the type of dietary protein consumed may play an important role in preventing the development of metabolic syndrome. In addition, previous studies reported the hypocholesterolemic effects of soy bioactive peptides and protein fractions [14].

Although several studies have reported that maternal diet affects metabolic disease development in adulthood, few studies have determined the alteration in organs and disease-related metabolism of young offspring. Previously, we have reported that the maternal consumption of low-isoflavone SPI significantly altered the hepatic gene expression profile of offspring. Much less effect was observed in response to genistein supplementation in the maternal diet [15]. Therefore, the aim of this study was to compare the effects of the early-life consumption of a low-isoflavone SPI diet and a casein diet supplemented with genistein on hepatic glucose and lipid metabolism of male offspring rats at postnatal day (PND) 21.

\section{Materials and Methods}

\subsection{Animals and Diets}

Seven-week-old virgin female Sprague-Dawley rats were obtained from the local animal facility (Orient Bio Inc., Seongnam, Korea) and were maintained in a temperature $\left(22 \pm 3{ }^{\circ} \mathrm{C}\right)$ and humidity $(50 \pm 10 \%)$-controlled room with a $12 \mathrm{~h}$ dark/light cycle. The experimental procedures used in the present study were approved by Seoul National University Institutional Animal Care and Use Committee (\#SNU-081006-4). As previously described [15], virgin female rats were randomly assigned into three groups after a one week acclimation period. Each group was offered the experimental diets containing casein (CAS diet), low-isoflavone SPI (SPI diet), or casein plus genistein (GEN diet: $250 \mathrm{mg} / \mathrm{kg}$ diet), which were prepared on the American Institute of Nutrition-93G formula, except that soybean oil was replaced with corn oil. The composition of diet is shown in Table 1. After two weeks of feeding, females were allowed to mate with mature males of the same strain (2:1). Female rats were maintained on their corresponding diet throughout pregnancy and lactation. Diets and water were provided ad libitum. The litter size and pup body weight were recorded at birth, and litters were adjusted to two females and six males to normalize the growth. Dams (CAS-D, SPI-D, and GEN-D groups) and their male offspring at age of PND 21 (CAS, SPI, and GEN groups) were sacrificed after an overnight fast. Blood samples were rapidly obtained by cardiac puncture. Tissues were removed, snap-frozen immediately in liquid nitrogen, and stored at $-80^{\circ} \mathrm{C}$ until use.

Table 1. Composition of experimental diet.

\begin{tabular}{cccc}
\hline \multirow{2}{*}{ Composition $(\mathbf{g} / \mathbf{k g})$} & \multicolumn{3}{c}{ Diet } \\
\cline { 2 - 4 } & CAS & SPI & GEN \\
\hline Cornstarch $_{\text {Casein }}{ }^{2}$ & 397.5 & 397.5 & 397.5 \\
Soy protein isolate $^{2}$ & 200 & - & 200 \\
Dextrinized cornstarch $_{\text {Sucrose }}$ & - & 200 & - \\
Corn oil & 132 & 132 & 132 \\
\hline
\end{tabular}


Table 1. Cont.

\begin{tabular}{cccc}
\hline \multirow{2}{*}{ Composition $(\mathbf{g} / \mathbf{k g})$} & \multicolumn{3}{c}{ Diet } \\
\cline { 2 - 4 } & CAS & SPI & GEN \\
\hline Fiber & 50 & 50 & 50 \\
Mineral mix & 35 & 35 & 35 \\
Vitamin mix & 10 & 10 & 10 \\
L-Cystine & 3 & 3 & 3 \\
Choline bitartrate & 2.5 & 2.5 & 2.5 \\
-Butylhydroquinone $_{\text {-Buistein }}{ }^{4}$ & 0.014 & 0.014 & 0.014 \\
Genit & - & - & 0.25
\end{tabular}

${ }^{1}$ Protevit-S (Lactoprot Deutschland GmbH, Kaltenkirchen, Germany); ${ }^{2}$ PRO-FAM ${ }^{\circledR} 974$ (ADM, Chicago, IL, USA); ${ }^{3}$ AIN-93G-MX (Dyets Inc., Bethlehem, PA, USA); ${ }^{4}$ AIN-93-VX (Dyets Inc., USA); ${ }^{5}$ Genistein (Chromadex Inc., Irvine, CA, USA). CAS, casein; SPI, low-isoflavone soy protein isolate; GEN, casein plus genistein.

\subsection{Serum Biochemical Analyses}

Blood was centrifuged at $10,000 \times g$ for $15 \mathrm{~min}$ and stored at $-80{ }^{\circ} \mathrm{C}$ until analyzed. Serum glucose, triglyceride, total cholesterol, and high-density lipoprotein (HDL) cholesterol levels were determined using commercial kits (Asan Pharmaceutical Co., Seoul, Korea). Serum free fatty acid levels were measured using a commercially available kit (Shinyang Diagnostics, Seoul, Korea). Serum hormones, including insulin (Millipore, Temecula, CA, USA), adiponectin (R\&D Systems, Minneapolis, MN, USA), and triiodothyronine (T3; GenWay Biotech, San Diego, CA, USA), were measured using an ELISA kit. The insulin resistance index was estimated by the homeostasis model assessment of insulin resistance (HOMA-IR) with the following formula: serum glucose $(\mathrm{mmol} / \mathrm{L}) \times$ serum insulin (mU/L)/22.5. Serum total homocysteine levels were determined by high performance liquid chromatography (HPLC) method according to previously described protocol [16].

\subsection{Serum Free Amino Acid Analysis}

Serum free amino acid levels were determined using the HPLC method, as previously described [17]. Briefly, serum samples were mixed with $2 \mathrm{mmol} / \mathrm{L}$ norvaline as an internal standard and $20 \%$ sulphosalicylic acid to precipitate protein. After centrifugation at $12,000 \times g$ for 5 min at $4{ }^{\circ} \mathrm{C}$, the supernatant containing free amino acid was removed and filtered. Samples and free amino acid standard (Agilent Technologies, Santa Clara, CA, USA) were analyzed by the Agilent 1200 HPLC equipped with an Inno C18 column ( $4.6 \mathrm{~mm} \times 150 \mathrm{~mm}, 5 \mu \mathrm{m}$, Young Jin Biochrom Co., Seongnam, Korea), and the fluorescence detector. The derivatization reagents of amino acids were o-phthalaldehyde (OPA) for the primary amino acids and 9-flurorenylmethyl chloroformate (FMOC) for proline. The analytes were eluted with a gradient of eluent $\mathrm{A}$ ( $20 \mathrm{~mm}$ phosphate buffer, $\mathrm{pH} 7.8)$ and eluent $\mathrm{B}$ (acetonitrile:methanol:water, 45:45:10, $v / v / v$ ) at a flow rate of $1.5 \mathrm{~mL} / \mathrm{min}$. The fluorescence detector was set at excitation $340 \mathrm{~nm}$ and emission $450 \mathrm{~nm}$ for OPA, and excitation $266 \mathrm{~nm}$ and emission $305 \mathrm{~nm}$ for FMOC.

\subsection{Oral Glucose Tolerance Test}

At 18-19 days of age, randomly selected four males per group with each offspring obtained from a different litter underwent the oral glucose tolerance test. Overnight-fasted offspring were given a single dose of oral glucose ( $2 \mathrm{~g} / \mathrm{kg}$ body weight), and blood samples were obtained from the tail vein periodically over a 2-h period prior to (time 0 ) and 30, 60, 90, and 120 min after the glucose load. Blood glucose levels were determined by using the Accu-Chek Advantage System (Roche Diagnostics, Indianapolis, IN, USA). Total area under the curve (AUC) during the oral glucose tolerance test was calculated using the trapezoidal rule.

\subsection{Hepatic Lipid Analyses}

Total lipids were extracted according to the method of Folch et al. [18]. Briefly, hepatic tissue was homogenized in 20 volumes $(w / v)$ of ice-cold phosphate buffered saline, and the protein content 
was measured using the commercial kit (Bio-Rad, Hercules, CA, USA). The homogenates containing $300 \mu \mathrm{g}$ of protein $(1 \mathrm{mg} / \mathrm{mL})$ were incubated in $1.2 \mathrm{~mL}$ of methanol-chloroform $(1: 2, v / v)$ at $4{ }^{\circ} \mathrm{C}$ for $3 \mathrm{~h}$. After incubation, $240 \mu \mathrm{L}$ of $0.88 \% \mathrm{KCl}$ was added for the aggregation of non-lipid contents, and centrifuged at $1000 \times g$ for $15 \mathrm{~min}$ at $4{ }^{\circ} \mathrm{C}$. The bottom layer was transferred to the new tube, and hepatic triglyceride and cholesterol levels were determined by enzymatic colorimetric methods using commercial kits (Asan Pharmaceutical Co., Seoul, Korea).

\subsection{Total RNA Extraction, Microarray Analysis and Real-Time PCR}

Total RNA of liver tissue was isolated using RNAiso Plus (Takara Bio Inc., Shiga, Japan), and the amount of RNA was measured using Quant-iT ${ }^{\mathrm{TM}}$ RNA Assay Kit (Invitrogen, Carlsbad, CA, USA). RNA purity and integrity were analyzed on an Agilent 2100 Bioanalyzer (Agilent Technologies, Santa Clara, CA, USA). Microarray hybridization was performed with the Illumina RatRef-12 v1.0 Expression BeadChip platform (San Diego, CA, USA). Samples from each group $(n=4)$ were analyzed by microarray. A detailed description of microarray hybridization and analysis was given in a previous study [15]. Further comprehensive analysis was performed on 119 differentially expressed genes with the fold change $\geq 1.5$ between two groups $(p<0.05)$. For real-time PCR, cDNA was synthesized using $2 \mu \mathrm{g}$ of total RNA with the Superscript ${ }^{\mathrm{TM}}$ II Reverse Transcriptase (Invitrogen, Carlsbad, CA, USA). Amplification reactions were performed using a StepOne ${ }^{\mathrm{TM}}$ Real-time PCR System (Applied Biosystems, Foster City, CA, USA) according to manufacturer's protocol. The selective gene expressions were determined by TaqMan ${ }^{\mathrm{TM}}$ - or $\mathrm{SYBR}^{\circledR}$ green-based detection. PCR primers are described in Supplementary Tables S1 and S2, respectively. Beta-actin was used as an endogenous control. Relative gene expression levels were analyzed using the $2^{-\Delta \Delta \mathrm{Ct}}$ method.

\subsection{Tissue Extraction and Immunoblotting}

Liver tissues were homogenized in ice-cold protein lysis buffer. Equal amounts of protein were loaded into the lanes of sodium dodecyl sulfate polyacrylamide gel electrophoresis gel, separated, and blotted onto a polyvinylidene difluoride membrane. After being blocked with 5\% nonfat milk or bovine serum albumin in Tris-buffered saline, membranes were probed with anti-phosphorylated AMP-activated protein kinase alpha ( $\mathrm{p}-\mathrm{AMPK} \alpha$ : Cell Signaling, Danvers, MA, USA) or beta-actin (Sigma-Aldrich, St. Louis, MO, USA). The membranes were then incubated with a secondary antibody for chemiluminescent detection. The band intensities were quantified with Quantity One software (Bio-Rad, Hercules, CA, USA).

\subsection{Statistical Analysis}

Statistical analyses were performed using IBM SPSS Statistics version 19.0 software (IBM SPSS Inc., Armonk, NY, USA). For all experiments, one-way analysis of variance (ANOVA) followed by Duncan's multiple range test or an independent $t$-test was used to determine statistical significance among the groups. Data were expressed as means \pm standard error of the mean (SEM), and differences were considered statistically significant at $p<0.05$. Correlation between two variables was analyzed by Pearson correlation coefficient.

\section{Results}

\subsection{Effects of Maternal Diet on Maternal Body Weight Changes and Serum Biochemical Parameters}

The body weight of dams fed an SPI or a GEN diet were not significantly different from those fed a CAS diet during the whole experimental period (Supplementary Figure S1). There was no significant difference in body weights of dams on postpartum day 21 (Table 2). Serum triglyceride, total cholesterol, and HDL cholesterol levels were significantly lower in dams fed an SPI diet compared with those in dams fed a CAS diet. Only HDL cholesterol levels were significantly lower in dams fed a GEN diet compared with dams fed a CAS diet. No significant differences in serum glucose, free fatty acids, and homocysteine levels 
were observed among groups. Consistent with observations in serum, hepatic triglyceride and cholesterol levels were significantly lower in the SPI-D group compared with the CAS-D and GEN-D groups.

Table 2. Effects of diets on the serum and hepatic biochemical parameters of dams.

\begin{tabular}{|c|c|c|c|}
\hline & \multicolumn{3}{|c|}{ Group } \\
\hline & CAS-D & SPI-D & GEN-D \\
\hline Body weight at sacrifice (g) & $299.5 \pm 12.6$ & $299.9 \pm 3.4$ & $304.0 \pm 11.2$ \\
\hline \multicolumn{4}{|l|}{ Serum } \\
\hline Glucose (mg/dL) & $94.5 \pm 6.6$ & $99.3 \pm 10.1$ & $104.2 \pm 13.3$ \\
\hline Triglyceride (mg/dL) & $81.8 \pm 10.4^{\mathrm{a}}$ & $48.7 \pm 7.3^{b}$ & $80.4 \pm 15.5^{\mathrm{a}}$ \\
\hline Total cholesterol (mg/dL) & $92.0 \pm 5.7^{\mathrm{a}}$ & $59.4 \pm 6.0^{b}$ & $77.0 \pm 8.2^{\mathrm{a}, \mathrm{b}}$ \\
\hline HDL cholesterol (mg/dL) & $74.8 \pm 4.9^{\mathrm{a}}$ & $49.0 \pm 4.8^{b}$ & $56.9 \pm 4.1^{b}$ \\
\hline Free fatty acids $(\mu \mathrm{mol} / \mathrm{L})$ & $722.1 \pm 88.5$ & $617.1 \pm 32.1$ & $694.9 \pm 75.4$ \\
\hline Homocysteine $(\mu \mathrm{mol} / \mathrm{L})$ & $6.9 \pm 0.4$ & $7.6 \pm 0.5$ & $6.9 \pm 0.4$ \\
\hline Insulin $(\mathrm{ng} / \mathrm{mL})$ & $0.5 \pm 0.1$ & $0.3 \pm 0.1$ & $0.9 \pm 0.4$ \\
\hline Adiponectin (ng/mL) & $6.7 \pm 0.4$ & $8.1 \pm 0.8$ & $6.3 \pm 0.7$ \\
\hline $\mathrm{T} 3(\mathrm{ng} / \mathrm{mL})$ & $1.7 \pm 0.1^{\mathrm{a}}$ & $1.4 \pm 0.1^{\mathrm{a}, \mathrm{b}}$ & $1.2 \pm 0.2^{b}$ \\
\hline \multicolumn{4}{|l|}{ Liver } \\
\hline Triglyceride ( $\mu \mathrm{g} / \mathrm{mg}$ protein) & $81.0 \pm 2.7^{\mathrm{a}}$ & $63.5 \pm 3.9^{b}$ & $87.3 \pm 5.2^{\mathrm{a}}$ \\
\hline Cholesterol ( $\mu \mathrm{g} / \mathrm{mg}$ protein) & $5.8 \pm 1.3^{\mathrm{a}}$ & $2.5 \pm 0.5^{b}$ & $5.4 \pm 0.6^{\mathrm{a}}$ \\
\hline
\end{tabular}

Data are means \pm standard error of the mean $(n=6-9$ for anthropometric and hepatic parameters, $n=5-8$ for serum parameters). Means in the same row with different superscript are significantly different at $p<0.05$. CAS-D, dams fed a casein diet; SPI-D, dams fed a low-isoflavone soy protein isolate diet; GEN-D, dams fed a casein plus genistein diet; HDL, high-density lipoprotein.

We also determined the serum levels of several hormones responsible for fetal growth and development, including insulin, adiponectin, and T3 [19,20], in dams to determine whether endocrine status was altered by diet (Table 2). The experimental diet did not affect the serum insulin or adiponectin levels of dams, but genistein supplementation significantly reduced serum T3 levels.

\subsection{Effect of Maternal Diet on Serum Amino Acid Levels in Dams}

As shown in Table 3, serum concentrations of aromatic amino acid (AAA), including tyrosine and tryptophan, were significantly higher in the SPI-D group compared with the CAS-D and GEN-D groups. Conversely, serum valine levels were significantly lower in the SPI-D group compared with the CAS-D group. The ratio of branched-chain amino acid (BCAA: isoleucine, leucine and valine) to AAA (phenylalanine, tryptophan and tyrosine) (BCAA/AAA) was significantly reduced by consumption of an SPI diet.

Table 3. Effects of diets on serum amino acid profiles in dams.

\begin{tabular}{cccc}
\hline \multirow{2}{*}{ Amino Acid $(\boldsymbol{\mu m o l} / \mathbf{L})$} & Group & \\
\cline { 2 - 4 } & CAS-D & SPI-D & GEN-D \\
\hline Alanine & $489.2 \pm 44.7$ & $464.5 \pm 33.7$ & $490.1 \pm 13.8$ \\
Arginine & $170.6 \pm 5.0$ & $191.3 \pm 13.3$ & $141.0 \pm 23.3$ \\
Asparagine & $76.8 \pm 3.6$ & $74.7 \pm 6.6$ & $72.2 \pm 1.5$ \\
Aspartate & $47.8 \pm 3.0$ & $48.8 \pm 9.4$ & $40.3 \pm 4.3$ \\
Glutamate & $186.9 \pm 9.2$ & $198.2 \pm 24.0$ & $203.6 \pm 24.0$ \\
Glutamine & $610.5 \pm 42.9$ & $550.7 \pm 34.1$ & $513.7 \pm 30.8$ \\
Glycine & $234.7 \pm 16.0$ & $255.6 \pm 25.8$ & $225.1 \pm 20.5$ \\
Histidine & $56.0 \pm 1.2$ & $52.1 \pm 2.8$ & $50.3 \pm 1.3$ \\
Isoleucine & $95.8 \pm 6.9$ & $80.1 \pm 3.4$ & $85.3 \pm 8.1$ \\
Leucine & $145.5 \pm 9.5$ & $117.6 \pm 5.7$ & $129.2 \pm 12.6$ \\
Lysine & $477.4 \pm 25.0$ & $477.7 \pm 62.0$ & $431.1 \pm 47.5$ \\
Methionine & $52.9 \pm 1.2^{\mathrm{a}}$ & $52.9 \pm 1.6^{\mathrm{a}}$ & $40.2 \pm 6.2^{\mathrm{b}}$ \\
Phenylalanine & $61.9 \pm 1.5^{\mathrm{a}, \mathrm{b}}$ & $63.2 \pm 3.4^{\mathrm{a}}$ & $54.1 \pm 2.6^{\mathrm{b}}$ \\
Proline & $172.4 \pm 6.5$ & $148.9 \pm 9.8$ & $169.5 \pm 11.2$ \\
\hline
\end{tabular}


Table 3. Cont.

\begin{tabular}{cccc}
\hline \multirow{2}{*}{ Amino Acid $(\mu \mathbf{m o l} / \mathbf{L})$} & \multicolumn{3}{c}{ Group } \\
\cline { 2 - 4 } & CAS-D & SPI-D & GEN-D \\
\hline Serine & $416.9 \pm 18.0$ & $401.3 \pm 24.8$ & $373.7 \pm 12.7$ \\
Threonine & $662.0 \pm 97.0$ & $426.3 \pm 37.3$ & $608.9 \pm 100.9$ \\
Tryptophan & $62.9 \pm 1.4^{\mathrm{b}}$ & $78.8 \pm 6.6^{\mathrm{a}}$ & $53.5 \pm 3.7^{\mathrm{b}}$ \\
Tyrosine & $47.8 \pm 1.9^{\mathrm{b}}$ & $64.6 \pm 5.8^{\mathrm{a}}$ & $46.2 \pm 3.2^{\mathrm{b}}$ \\
Valine & $152.4 \pm 8.6^{\mathrm{a}}$ & $119.4 \pm 3.5^{\mathrm{b}}$ & $137.7 \pm 10.4^{\mathrm{a}, \mathrm{b}}$ \\
\hline BCAA & $393.7 \pm 24.6$ & $317.1 \pm 12.4$ & $352.1 \pm 30.7$ \\
AAA & $172.5 \pm 2.7^{\mathrm{b}}$ & $206.6 \pm 11.0^{\mathrm{a}}$ & $153.9 \pm 7.3^{\mathrm{b}}$ \\
BCAA/AAA & $2.3 \pm 0.1^{\mathrm{a}}$ & $1.5 \pm 0.1^{\mathrm{b}}$ & $2.3 \pm 0.2^{\mathrm{a}}$ \\
\hline
\end{tabular}

Data are means $\pm \operatorname{SEM}(n=5)$. Means in the same row with different superscript are significantly different at $p<0.05$. BCAA, branched-chain amino acids (isoleucine, leucine and valine); AAA, aromatic amino acids (phenylalanine, tryptophan and tyrosine).

\subsection{Effects of Maternal Diet on Growth and Glucose Metabolism of Offspring}

The body weights of offspring of dams fed an SPI diet were significantly lower than those of the other groups, starting from PND 12, up to the end of the experiment (Figure 1a). There were no significant differences in serum glucose levels (CAS: 65.1 \pm 4.6 ; SPI: $59.3 \pm 4.4$; GEN: $55.2 \pm 4.2 \mathrm{mg} / \mathrm{dL}$ ), serum insulin levels (CAS: $0.74 \pm 0.37$; SPI: $0.46 \pm 0.12$; GEN: $0.72 \pm 0.29 \mathrm{ng} / \mathrm{mL}$ ), and HOMA-IR (CAS: $2.7 \pm 1.3$; SPI: $1.6 \pm 0.6$; GEN: $2.6 \pm 1.3$ ) among the offspring groups, although the values of the SPI group tended to be lower than those of the other two groups. We also investigated whether insulin signaling was altered by the maternal diet using the oral glucose tolerance test, and observed no significant differences in blood glucose levels and total AUC for glucose among the groups (Figure 1b,c).

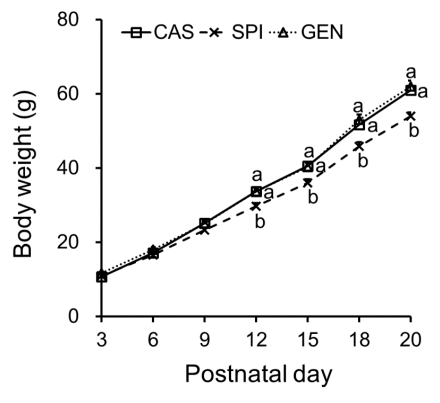

(a)

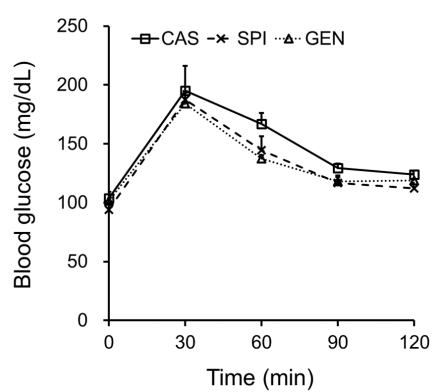

(b)

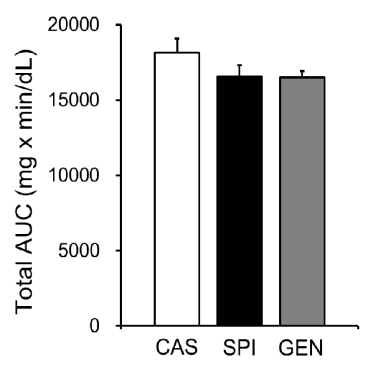

(c)

Figure 1. Effects of maternal diet on (a) body weight change $(n=14-17)$ and $(\mathbf{b}, \mathbf{c})$ glucose metabolism in male offspring $(n=4)$. Blood glucose curve and total area under the curve (AUC) in response to a glucose-loading test. Data are means \pm standard error of the mean. Means with different superscripts are significantly different at $p<0.05$. CAS, offspring of dams fed a casein diet; SPI, offspring of dams fed a low-isoflavone soy protein isolate diet; GEN, offspring of dams fed a casein plus genistein diet.

\subsection{Effects of Maternal Diet on Lipid Metabolism of Offspring}

Serum triglyceride levels were significantly lower in the SPI group than the CAS and GEN groups (Figure 2a), and free fatty acid levels were significantly lower in the SPI group than the GEN group (Figure 2b). Maternal intake of SPI and GEN diets significantly reduced serum total cholesterol levels in offspring (Figure 2c). Although serum HDL cholesterol levels were significantly lower in the SPI group compared with the CAS group (Figure 2d), the ratio of HDL cholesterol to total cholesterol was not significantly different between the CAS and SPI groups (Figure 2e). In contrast, the ratio was significantly increased by maternal consumption of the GEN diet. Unlike their dams, the offspring did not show any significant differences in hepatic triglyceride or cholesterol concentrations (Figure 2f,g), 
which suggests that the decreases in serum triglyceride levels in the SPI group were not simply due to hepatic triglyceride accumulation.

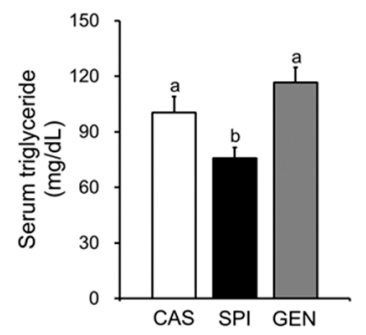

(a)

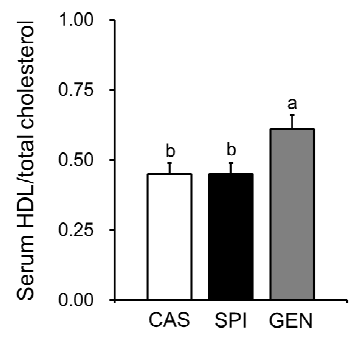

(e)

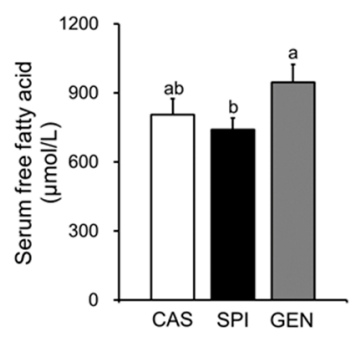

(b)

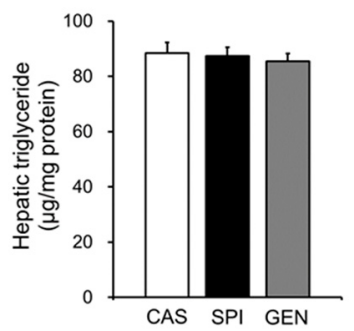

(f)

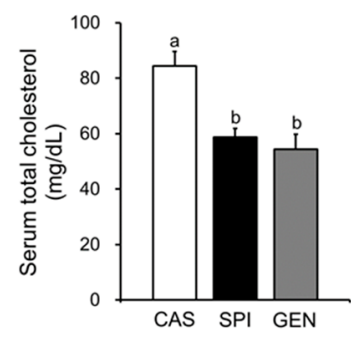

(c)

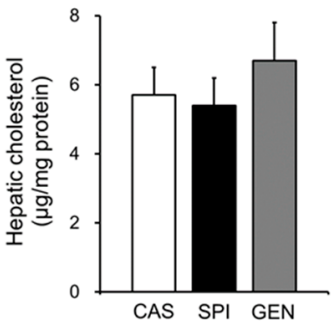

(g)

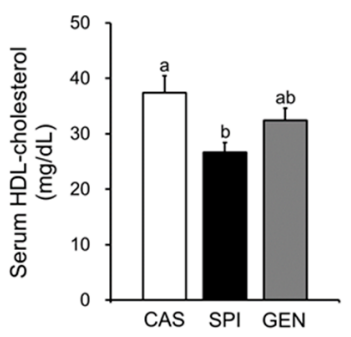

(d)

Figure 2. Effects of maternal diet on lipid metabolism of male offspring. (a) Serum triglyceride, (b) free fatty acid, (c) total cholesterol, (d) high-density lipoprotein (HDL) cholesterol levels, and (e) the ratio of HDL cholesterol to total cholesterol $(n=8-10)$; (f) Hepatic triglyceride and (g) cholesterol levels $(n=9-11)$. Data are means \pm standard error of the mean. Means with different superscripts are significantly different at $p<0.05$.

\subsection{Effects of Maternal Diet on Hepatic Gene Expressions Involved in Lipid Metabolism of Offspring}

Previously, gene ontology analysis of microarray data showed that 58 genes related to "lipid, fatty acid and steroid metabolism" are significantly affected by maternal diet [15]. Therefore, we confirmed the mRNA levels of major genes involved in triglyceride metabolism (Figure 3a) and cholesterol metabolism (Figure 3b) by real-time PCR. A triglyceride-lowering effect of SPI was supported by higher hepatic mRNA levels of several genes involved in lipolysis and lipid oxidation, including Lpl, $\mathrm{Cpt1b}$ and Hadh compared with those of the CAS group. An increased expression of Lpl has been reported to be involved in the increased hepatic uptake of circulating triglycerides [21], especially around birth and throughout the suckling period [22]. The present study also confirms an increased fatty acid beta-oxidation in the offspring of dams fed an SPI diet, which have significantly higher mRNA levels of Cpt1b and Hadh than the offspring of dams fed a CAS diet. Fetal liver has been shown to contain a mixture of adult liver- and muscle-type of CPT1 [23]. Thus, an increased fatty acid oxidation may occur to compensate for an increased uptake of free fatty acids into the liver, thereby resulting in similar hepatic triglyceride levels between the CAS and SPI groups. Additional downregulation of mRNA levels of a lipogenic gene, Fasn, may contribute to the hypotriglyceridemic effect of the maternal SPI diet compared with the maternal GEN diet. The mRNA levels of other lipogenic genes, Thrsp and Scd1, tended to be lower in the SPI group compared with the CAS and GEN groups. 


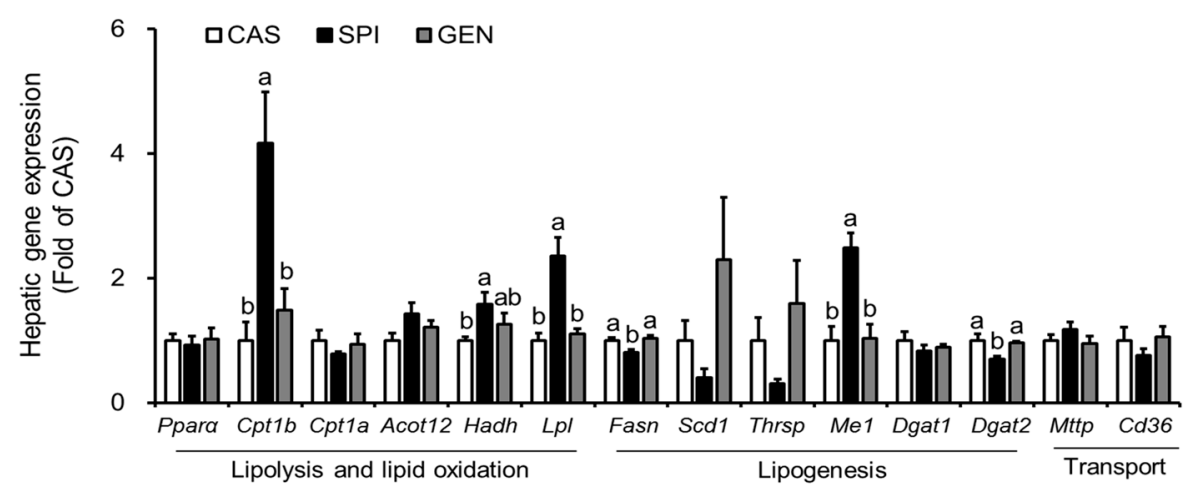

(a)

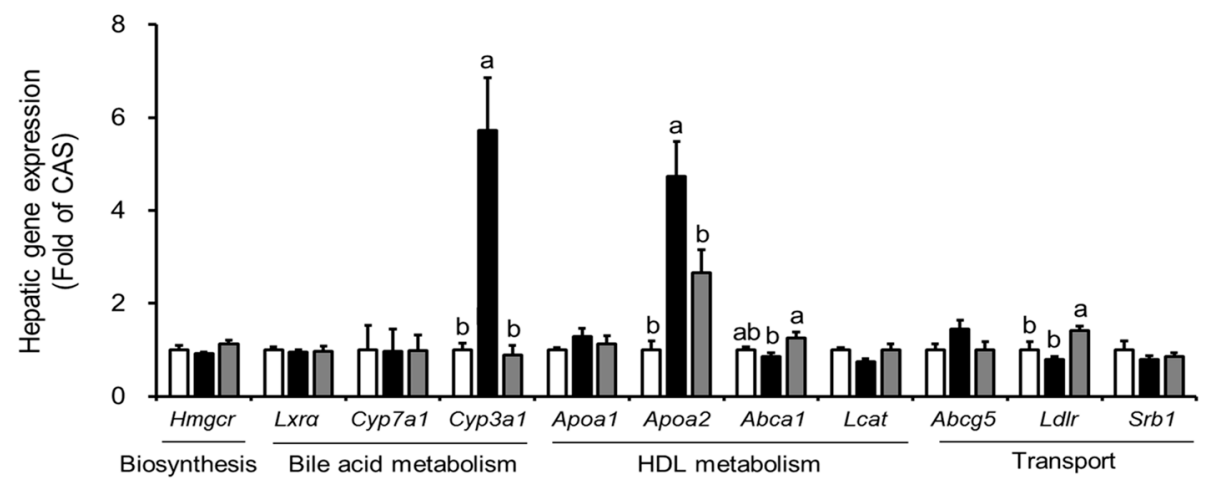

(b)

Figure 3. Effects of maternal diet on hepatic gene expression related to the lipid metabolism of male offspring. (a) Triglyceride metabolism; (b) Cholesterol metabolism. Relative mRNA level of each gene was determined by real-time PCR. Beta-actin was used as an endogenous control. Data are means \pm standard error of the mean $(n=4)$. Means with different superscripts are significantly different at $p<0.05$.

We found that the hepatic expression of some selected genes important in the cholesterol metabolism was also altered by maternal diet (Figure $3 b$ ). There was a distinct regulation of gene expression in the offspring by maternal SPI and GEN diet. In the SPI group, mRNA levels of Cyp3a1, a gene that plays an important role in the hydroxylation and excretion of bile acid in the liver [24], were significantly higher compared with those in the CAS and GEN groups. Maternal consumption of a GEN diet, but not an SPI diet, significantly increased the mRNA levels of $L d l r$, suggesting that increased lipoprotein uptake may be involved in the hypocholesterolemic effect observed in the GEN group. Furthermore, we observed that significantly higher Abca1 mRNA levels in the GEN group compared with the SPI group suggested the increased reverse cholesterol transport, as indicated by the ratio of HDL cholesterol to total cholesterol. In contrast, Lcat mRNA levels were significantly lower in the SPI group compared with the CAS group ( $p=0.020$, by $t$-test), which suggested an inhibition of pre-beta HDL (nascent HDL) maturation to alpha-HDL (mature HDL) in the SPI group. Apoa 2 mRNA levels were significantly increased by maternal SPI consumption. Therefore, the maturation of nascent HDL rather than the biosynthesis of nascent HDL may be suppressed in the SPI group compared with the other two groups. For comparison, microarray data are shown in Supplementary Figure S2.

3.6. Effects of Maternal Diet on the Activation of Peroxisome Proliferator-Activated Receptor Alpha (PPAR $\alpha)$ Signaling Pathway in the Liver of Offspring

Maternal diet did not alter mRNA levels of PPAR $\alpha$, a gene encoding a key transcription factor that regulates many aspects of lipid metabolism such as fatty acid oxidation, uptake, and transport, in the liver of offspring. However, we observed increased expressions of PPAR $\alpha$ target genes, including Me1, 
Cpt1b, Lpl, Cyp3a1, and Apoa2 in the livers of the SPI group (Figure 3a,b). To confirm the altered PPAR $\alpha$ signaling pathway in the SPI group, we identified 11 PPAR $\alpha$ target genes among 119 differentially expressed genes in response to maternal diet $(p<0.05)$ with a fold change equal to or greater than 1.5 between any two groups based on a previous study [25]. Most genes, except $C y p 2 c 12$, were significantly induced in response to maternal SPI diet (Figure 4a). A previous study reported that Cyp2c12 was downregulated by peroxisome proliferators [26]. Furthermore, serum levels of adiponectin, which is associated with the activation of PPAR $\alpha$ pathways [27], were significantly increased in the SPI group compared with the CAS group (Figure 4b). Furthermore, the activation of AMPK, another downstream pathway of adiponectin in the liver, was significantly induced in the SPI group compared with the CAS group (Figure $4 c, d$ ).
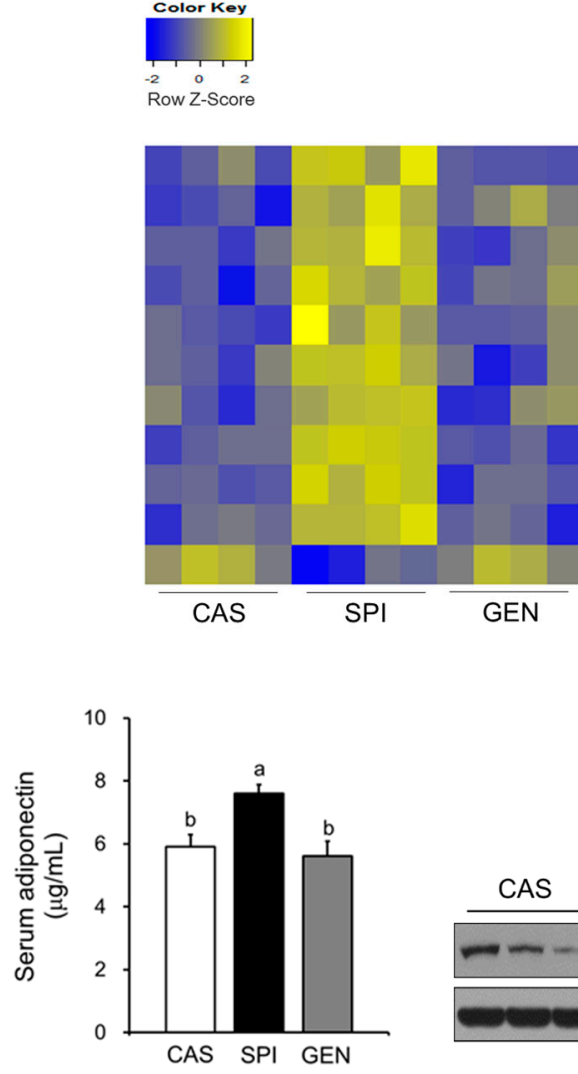

(b)

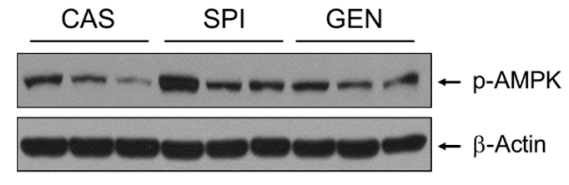

(c)

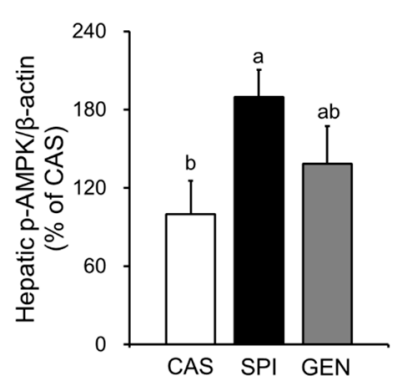

(d)

Figure 4. Effects of maternal diet on hepatic expressions of peroxisome proliferator-activated receptor alpha (PPAR $\alpha$ )-target genes of male offspring. (a) Visualization of gene expression levels as a heat map. Data were Z-score normalized. Each cell represents the individual differentially expressed genes in each offspring liver sample $(n=4)$. Yellow color represents the up-regulated gene expression and blue color represents the down-regulated gene expression. ${ }^{*} p<0.05$ and ${ }^{* *} p<0.01$ for maternal diet effect among groups; (b) Serum adiponectin $(n=9)$ was measured by ELISA; (c,d) Hepatic phosphorylated AMP-activated protein kinase (p-AMPK) protein levels were determined by immunoblotting $(n=4-5)$. Data are means \pm standard error of the mean. Means with different superscripts are significantly different at $p<0.05$.

\subsection{Effects of Maternal Biochemical Parameters on the Regulation of Lipid Metabolism of Offspring}

To investigate the related maternal factors determining the lipid metabolism of offspring, we investigated the association between the serum biochemical parameters of dams and the anthropometrical and serum biochemical parameters of offspring. Previously, we have reported 
that the SPI group had significantly lower body weight and relative adipose tissue weight and significantly higher relative liver weight compared with the CAS group [15]. Offspring body weight was negatively associated with the serum AAA levels in dams, whereas the relative liver weight was positively associated with the serum AAA levels of dams (Figure 5a,b). We also observed a significant correlation between the serum triglyceride levels of offspring and the serum AAA levels of dams (Figure 5c), but not with the serum triglyceride levels of dams $(p=0.177)$. The serum cholesterol levels of offspring were significantly associated with serum cholesterol (Figure 5d) and the HDL cholesterol levels of dams (Figure 5e). There were no significant associations between serum insulin, adiponectin, and T3 levels in dams, and the anthropometrical parameters and serum lipid levels of offspring (data not shown).

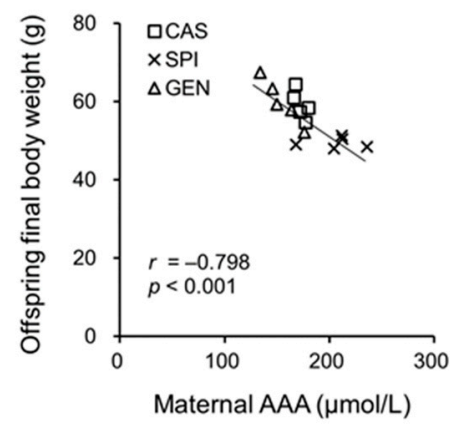

(a)

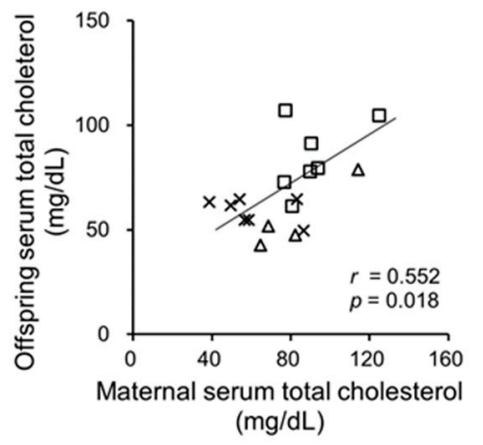

(d)

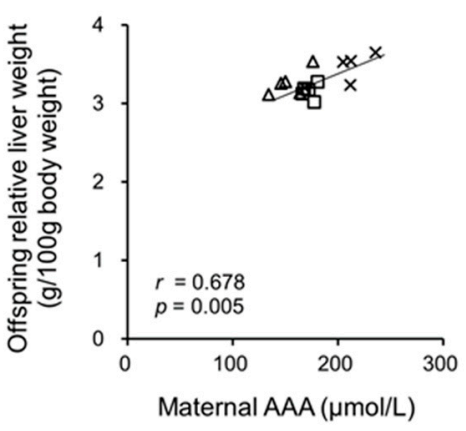

(b)

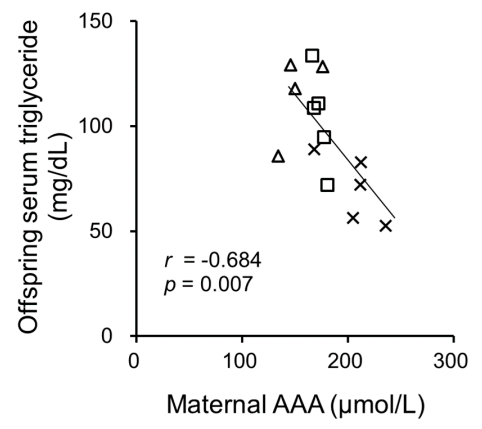

(c)

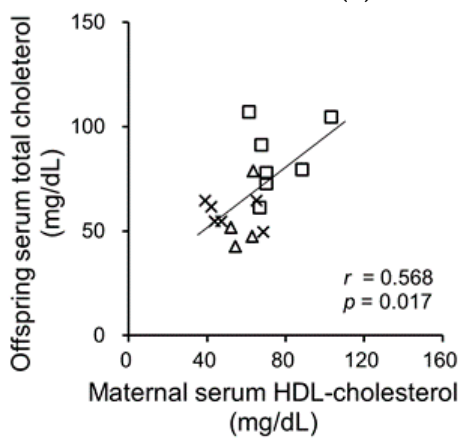

(e)

Figure 5. Correlation between (a) serum AAA levels in dams and body weight; (b) serum AAA levels in dams and relative liver weight of offspring; (c) serum AAA levels in dams and serum triglyceride levels in offspring; (d) serum total cholesterol levels in dams and serum total cholesterol levels in offspring; (e) serum high-density lipoprotein (HDL) cholesterol levels in dams and serum total cholesterol levels in offspring AAA, aromatic amino acid. Pearson correlation coefficient, $r$ and $p$-value are indicated.

Pearson correlation coefficients were calculated between the serum biochemical variables that were significantly different among the dam groups, and the mRNA levels of PPAR $\alpha$-target genes in offspring (Figure 6). Most mRNA levels of PPAR $\alpha$-target genes showed strong positive correlations with serum tyrosine and AAA levels in dams. 


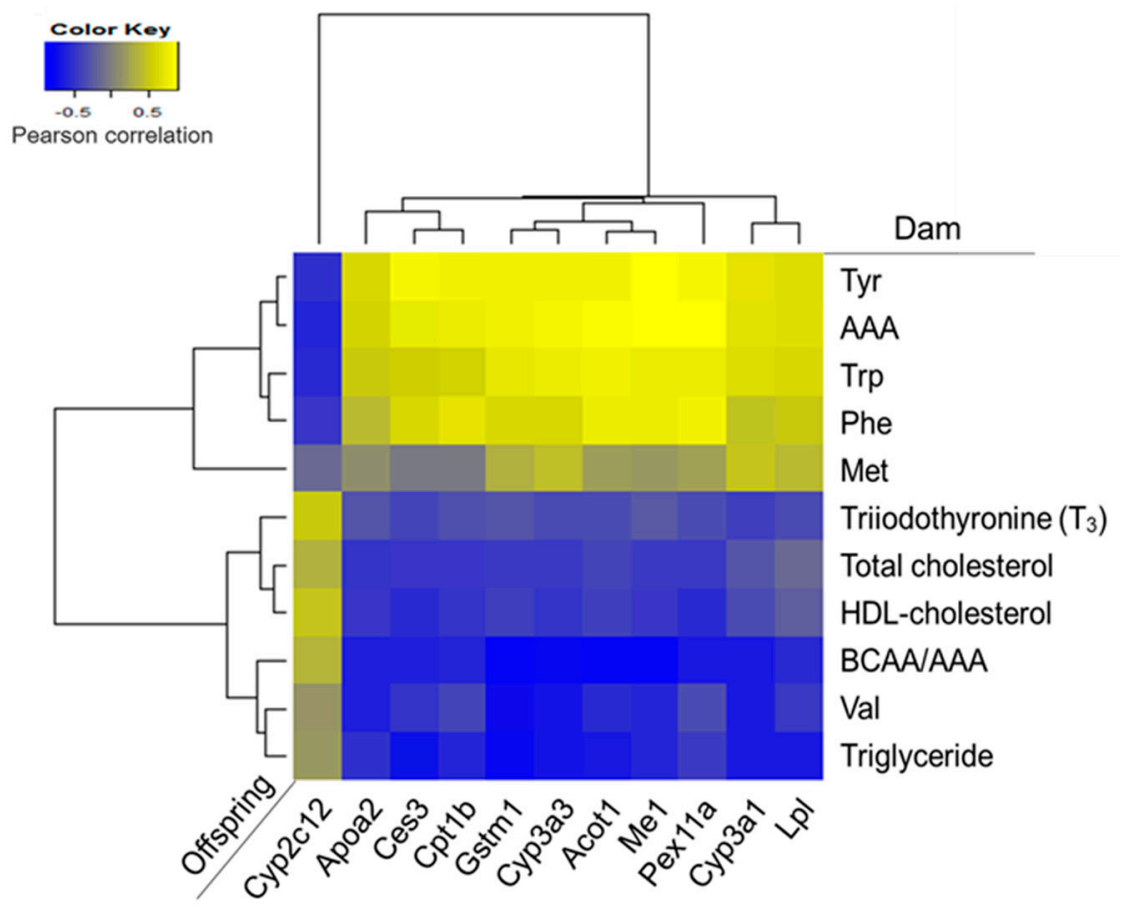

Figure 6. Heat map of Pearson correlation coefficients between serum parameters in dams and hepatic expressions of PPAR $\alpha$-target genes in offspring. Yellow color represents positive correlation and blue color represents negative correlation.

\section{Discussion}

Several studies have suggested that the consumption of isoflavone with soy protein has different biological effects than the consumption of isoflavone without soy protein [28]. Previously, we have reported that maternal intake of low-isoflavone SPI significantly reduced body weights and induced liver growth retardation in offspring, with substantial effects on hepatic gene expression [15]. Therefore, we investigated whether dietary protein source and isoflavone contents in the maternal diet would regulate the lipid metabolism in their offspring on PND 21. Lipid metabolism-related genes were shown to be significantly upregulated in mouse liver during PND 7-PND 21 [29].

In the present study, serum triglyceride, total cholesterol, and HDL cholesterol levels were significantly lower in the SPI group compared with the CAS group. In contrast, only total serum cholesterol levels were significantly lower in the GEN group compared with the CAS group, resulting in a significant increase in the ratio of HDL cholesterol to total cholesterol. No significant differences in hepatic triglyceride and cholesterol levels were observed among the groups. Maternal SPI consumption attenuated serum lipid levels in offspring by reducing hepatic lipogenesis, increasing fatty acid oxidation, and enhancing bile acid catabolism based on the hepatic mRNA levels of related genes.

Although both serum triglyceride and total cholesterol levels were decreased in the SPI group compared to the CAS group, it seems that different mechanisms are involved in maternal effects on lipid metabolism of offspring. Triglycerides in milk are about 100-fold higher than those in the serum of dams and their offspring [30], suggesting that lower serum triglyceride levels in the SPI group were not due to lower triglyceride levels in the milk of their dams. Meanwhile, dams at 21 days of suckling fed a soy protein diet showed lower cholesterol levels in serum, liver, and milk compared with dams fed a casein diet [31]. Similarly, maternal flaxseed diet during lactation decreased cholesterol levels in milk and serum of offspring [32]. Therefore, cholesterol contents in milk could possibly affect serum cholesterol levels. 
In consideration of the regulatory role of PPAR $\alpha$ on lipid metabolism in adults, we examined whether PPAR $\alpha$ activation in offspring is altered by maternal diet. Our results clearly showed increased expressions of target genes of PPAR $\alpha$ in the SPI group, which may be responsible for the hypolipidemia observed in the SPI group. PPAR $\alpha$ has been shown to regulate the transcription of genes involved in glucose and lipid metabolism, liver inflammation, and hepatocyte proliferation (especially in rodents) [25]. Besides natural ligands, including fatty acids and their metabolites, various xenobiotics are shown to activate PPARs [33]. Indeed, we observed increases in the mRNA levels of genes involved in xenobiotics and drug metabolism. The altered levels of xenobiotics were possibly due to the retarded liver development, and may activate PPAR $\alpha$ in the SPI group [15]. Interestingly, the mRNA levels of PPAR $\alpha$-target genes, including Me1, Cpt1b, Lpl, Cyp3a1, and Apoa2 were significantly associated with the relative liver weight of offspring (data not shown). Similarly, the induction of dyslipidemia in offspring by a maternal low-protein diet (9\% vs. 18\%) during pregnancy involves an altered epigenetic regulation of specific transcription factors, including PPAR $\alpha$, in the liver of offspring [34]. Indeed, a recent study reported the increased gene expressions of the PPAR $\alpha$ pathway (Cyp7a1, Aqp7, Lpl and $C p t 1 b)$ by maternal low-protein diet ( $8 \%$ protein) throughout pregnancy and lactation in the liver of mice offspring [35]. Furthermore, the maternal consumption of oxidized fat during pregnancy upregulates expression of PPAR $\alpha$-target genes with lowered triglyceride concentrations in both dam and fetal livers [36].

Although structure-activity relationship studies showed a direct binding of isoflavones to PPARs [37], we did not observe the PPAR $\alpha$ activation in the livers of GEN diet-fed dams (data not shown) and their offspring. Instead, we observed the significant increase in Ldlr mRNA levels in the GEN group. Consistently, a previous study showed a higher expression of the Ldlr gene in male Zucker rats fed a high-isoflavone diet compared with casein-fed rats, but not in rats fed a protein diet with similar amino acid profiles (low methionine/glycine and low lysine/arginine) with SPI for six weeks [38].

A previous study proposed that non-isoflavone phytochemicals and their metabolites, or the altered protein/peptide composition during isoflavone-removal processing, may be responsible for the effect of SPI on PPAR $\alpha$ activation [39]. A recent cell culture study reported that the soybean-derived dipeptide Trp-Glu is a key hypolipidemic compound via PPAR $\alpha$ activation [40]. Here, we did not observe a higher activation of PPAR $\alpha$ in dams fed an SPI compared with dams fed a CAS diet (data not shown), which suggested that hormonal or metabolic changes induced in dams may be responsible for PPAR $\alpha$ activation in the SPI group.

Maternal consumption of a SPI diet significantly decreased serum BCAA/AAA in dams compared with a CAS diet (1.5 vs. 2.3). In normal animals, the BCAA/AAA ratio in plasma is about 3:1 [41]. Previous studies reported decreases in maternal BCAA plasma concentrations in intrauterine growth restriction (IUGR) models with dams fed a low-protein diet, and in $L d l r^{-/-}$dams fed a Western diet [42,43]. Similarly, IUGR induced by calorie restriction decreased plasma concentrations of BCAAs [44]. In the same study, BCAA supplementation effectively increased plasma BCAA levels and improved the physiological functions of uterus and placenta, resulting in increased litter size and embryo weight [44]. These results suggest that the altered amino acid profile, especially lowered BCAA concentrations, may be responsible for some of the phenotypes observed in the offspring of IUGR models. We consistently observed a significant negative correlation between the serum AAA levels in dams and the body weight of offspring at PND 21. Moreover, maternal AAA concentration was significantly correlated with serum triglyceride levels and PPAR $\alpha$-target gene expressions in offspring. Further research is warranted to investigate the underlying mechanism for the association between maternal AAA levels and PPAR $\alpha$ activation in offspring.

\section{Conclusions}

Maternal consumption of low-isoflavone SPI and genistein differently regulated serum lipid parameters and hepatic gene expressions involved in lipid metabolism in offspring. Interestingly, 
more pronounced effects on lipid metabolism were observed in the offspring of SPI diet-fed dams, suggesting the important role of maternal SPI consumption regardless of isoflavone levels in the lipid metabolism regulation of offspring.

Supplementary Materials: The following are available online at www.mdpi.com/2072-6643/9/9/1039/s1. Table S1: List of primers used for real-time PCR (TaqMan); Table S2: Primer sequences for real-time PCR (SYBR green); Figure S1: Effects of diet on body weight of dams during pre-pregnancy, pregnancy and lactation. Data are means \pm standard effort of the mean $(n=6-9)$. Means with different superscripts are significantly different at $p$ $<0.05$. CAS-D, dams fed a casein diet; SPI-D, dams fed a low-isoflavone soy protein isolate diet; GEN-D, dams fed a casein plus genistein diet; Figure S2: Effects of maternal diet on hepatic gene expression related to lipid metabolism of male offspring. Each column of heat map represents the mean of the individual differentially expressed genes in maternal diet group $(n=4)$. Data were Z-score normalized. Yellow color represents the up-regulated gene expression compared to the mean, whereas blue color represents the down-regulated gene expression below the mean.

Acknowledgments: This research was supported by Basic Science Research Program through the National Research Foundation of Korea funded by the Ministry of Education, Science and Technology (KRF-2008-313-C00968).

Author Contributions: Y.H.K. conceived and designed the experiments; A.H. and S.B.W. performed the experiments; A.H., S.B.W. and Y.H.K. analyzed the data; A.H., S.B.W. and Y.H.K. wrote the paper.

Conflicts of Interest: The authors declare no conflict of interest. The funding sponsors had no role in the design of the study; in the collection, analyses, or interpretation of data; in the writing of the manuscript, and in the decision to publish the results.

\section{References}

1. Gluckman, P.D.; Hanson, M.A.; Cooper, C.; Thornburg, K.L. Effect of in utero and early-life conditions on adult health and disease. N. Engl. J. Med. 2008, 359, 61-73. [CrossRef] [PubMed]

2. Wu, G.; Bazer, F.W.; Cudd, T.A.; Meininger, C.J.; Spencer, T.E. Maternal nutrition and fetal development. J. Nutr. 2004, 134, 2169-2172. [PubMed]

3. Chango, A.; Pogribny, I.P. Considering maternal dietary modulators for epigenetic regulation and programming of the fetal epigenome. Nutrients 2015, 7, 2748-2770. [CrossRef] [PubMed]

4. Ascencio, C.; Torres, N.; Isoard-Acosta, F.; Gomez-Perez, F.J.; Hernandez-Pando, R.; Tovar, A.R. Soy protein affects serum insulin and hepatic SREBP-1 mRNA and reduces fatty liver in rats. J. Nutr. 2004, 134, 522-529. [PubMed]

5. Tovar, A.R.; Torre-Villalvazo, I.; Ochoa, M.; Elias, A.L.; Ortiz, V.; Aguilar-Salinas, C.A.; Torres, N. Soy protein reduces hepatic lipotoxicity in hyperinsulinemic obese Zucker fa/fa rats. J. Lipid. Res. 2005, 46, 1823-1832. [CrossRef] [PubMed]

6. Gudbrandsen, O.A.; Wergedahl, H.; Liaset, B.; Espe, M.; Berge, R.K. Dietary proteins with high isoflavone content or low methionine-glycine and lysine-arginine ratios are hypocholesterolaemic and lower the plasma homocysteine level in male Zucker fa/fa rats. Br. J. Nutr. 2005, 94, 321-330. [CrossRef] [PubMed]

7. Badger, T.M.; Ronis, M.J.; Wolff, G.; Stanley, S.; Ferguson, M.; Shankar, K.; Simpson, P.; Jo, C.H. Soy protein isolate reduces hepatosteatosis in yellow Avy/a mice without altering coat color phenotype. Exp. Biol. Med. 2008, 233, 1242-1254. [CrossRef] [PubMed]

8. Souzeau, E.; Belanger, S.; Picard, S.; Deschepper, C.F. Dietary isoflavones during pregnancy and lactation provide cardioprotection to offspring rats in adulthood. Am. J. Physiol.-Heart Circ. Physiol. 2005, 289, H715-H721. [CrossRef] [PubMed]

9. Simmen, F.A.; Mercado, C.P.; Zavacki, A.M.; Huang, S.A.; Greenway, A.D.; Kang, P.; Bowman, M.T.; Prior, R.L. Soy protein diet alters expression of hepatic genes regulating fatty acid and thyroid hormone metabolism in the male rat. J. Nutr. Biochem. 2010, 21, 1106-1113. [CrossRef] [PubMed]

10. Fukui, K.; Tachibana, N.; Wanezaki, S.; Tsuzaki, S.; Takamatsu, K.; Yamamoto, T.; Hashimoto, Y.; Shimoda, T. Isoflavone-free soy protein prepared by column chromatography reduces plasma cholesterol in rats. J. Agric. Food Chem. 2002, 50, 5717-5721. [CrossRef] [PubMed]

11. Shukla, A.; Brandsch, C.; Bettzieche, A.; Hirche, F.; Stangl, G.I.; Eder, K. Isoflavone-poor soy protein alters the lipid metabolism of rats by SREBP-mediated down-regulation of hepatic genes. J. Nutr. Biochem. 2007, 18, 313-321. [CrossRef] [PubMed] 
12. Sugiyama, K.; Ohkawa, S.; Muramatsu, K. Relationship between amino acid composition of diet and plasma cholesterol level in growing rats fed a high cholesterol diet. J. Nutr. Sci. Vitaminol. 1986, 32, 413-423. [CrossRef] [PubMed]

13. Gannon, M.C.; Nuttall, J.A.; Nuttall, F.Q. The metabolic response to ingested glycine. Am. J. Clin. Nutr. 2002, 76, 1302-1307. [PubMed]

14. Ramdath, D.D.; Padhi, E.M.; Sarfaraz, S.; Renwick, S.; Duncan, A.M. Beyond the Cholesterol-Lowering Effect of Soy Protein: A Review of the Effects of Dietary Soy and Its Constituents on Risk Factors for Cardiovascular Disease. Nutrients 2017, 9. [CrossRef] [PubMed]

15. Won, S.B.; Han, A.; Kwon, Y.H. Maternal consumption of low-isoflavone soy protein isolate alters hepatic gene expression and liver development in rat offspring. J. Nutr. Biochem. 2017, 42, 51-61. [CrossRef] [PubMed]

16. Minniti, G.; Piana, A.; Armani, U.; Cerone, R. Determination of plasma and serum homocysteine by high-performance liquid chromatography with fluorescence detection. J. Chromatogr. A 1998, 828, 401-405. [CrossRef]

17. Yoon, M.; Won, S.B.; Kwon, Y.H. Altered lipid metabolism in rat offspring of dams fed a low-protein diet containing soy protein isolate. Life Sci. 2017, 174, 1-7. [CrossRef] [PubMed]

18. Folch, J.; Lees, M.; Stanley, G.H.S. A simple method for the isolation and purification of total lipids from animal tissues. J. Biol. Chem. 1957, 226, 497-509. [PubMed]

19. Forhead, A.J.; Fowden, A.L. Thyroid hormones in fetal growth and prepartum maturation. J. Endocrinol. 2014, 221, R87-R103. [CrossRef] [PubMed]

20. Aye, I.L.; Powell, T.L.; Jansson, T. Review: Adiponectin-The missing link between maternal adiposity, placental transport and fetal growth? Placenta 2013, 34, S40-S45. [CrossRef] [PubMed]

21. Grinberg, D.R.; Ramirez, I.; Vilaro, S.; Reina, M.; Llobera, M.; Herrera, E. Starvation enhances lipoprotein lipase activity in the liver of the newborn rat. Biochim. Biophys. Acta (BBA)-Lipids Lipid Metab. 1985, 833, 217-222. [CrossRef]

22. Panadero, M.; Bocos, C.; Herrera, E. Relationship between lipoprotein lipase and peroxisome proliferator-activated receptor- $\alpha$ expression in rat liver during development. J. Physiol. Biochem. 2006, 62, 189-198. [CrossRef] [PubMed]

23. Saggerson, E.D.; Carpenter, C.A. Carnitine palmitoyltransferase in liver and five extrahepatic tissues in the rat. Inhibition by DL-2-bromopalmitoyl-CoA and effect of hypothyroidism. Biochem. J. 1986, 236, 137-141. [CrossRef] [PubMed]

24. Xie, W.; Radominska-Pandya, A.; Shi, Y.; Simon, C.M.; Nelson, M.C.; Ong, E.S.; Waxman, D.J.; Evans, R.M. An essential role for nuclear receptors SXR/PXR in detoxification of cholestatic bile acids. Proc. Natl. Acad. Sci. USA 2001, 98, 3375-3380. [CrossRef] [PubMed]

25. Rakhshandehroo, M.; Knoch, B.; Muller, M.; Kersten, S. Peroxisome proliferator-activated receptor alpha target genes. PPAR Res. 2010, 2010. [CrossRef] [PubMed]

26. Fan, L.Q.; Brown-Borg, H.; Brown, S.; Westin, S.; Mode, A.; Corton, J.C. PPARalpha activators down-regulate CYP2C7, a retinoic acid and testosterone hydroxylase. Toxicology 2004, 203, 41-48. [CrossRef] [PubMed]

27. Yamauchi, T.; Nio, Y.; Maki, T.; Kobayashi, M.; Takazawa, T.; Iwabu, M.; Okada-Iwabu, M.; Kawamoto, S.; Kubota, N.; Kubota, T.; et al. Targeted disruption of AdipoR1 and AdipoR2 causes abrogation of adiponectin binding and metabolic actions. Nat. Med. 2007, 13, 332-339. [CrossRef] [PubMed]

28. Messina, M. Soy and health update: Evaluation of the clinical and epidemiologic literature. Nutrients 2016. [CrossRef] [PubMed]

29. Li, T.; Huang, J.; Jiang, Y.; Zeng, Y.; He, F.; Zhang, M.Q.; Han, Z.; Zhang, X. Multi-stage analysis of gene expression and transcription regulation in C57/B6 mouse liver development. Genomics 2009, 93, 235-242. [CrossRef] [PubMed]

30. McMullin, T.S.; Lowe, E.R.; Bartels, M.J.; Marty, M.S. Dynamic changes in lipids and proteins of maternal, fetal, and pup blood and milk during perinatal development in CD and Wistar rats. Toxicol. Sci. 2008, 105, 260-274. [CrossRef] [PubMed]

31. Lu, Y.F.; Jian, M.R. Effects of soy protein and casein on lipid metabolism in mature and suckling rats. Nutr. Res. 1997, 17, 1341-1350. [CrossRef] 
32. Troina, A.A.; Figueiredo, M.S.; Moura, E.G.; Boaventura, G.T.; Soares, L.L.; Cardozo, L.F.; Oliveira, E.; Lisboa, P.C.; Passos, M.A.; Passos, M.C. Maternal flaxseed diet during lactation alters milk composition and programs the offspring body composition, lipid profile and sexual function. Food Chem. Toxicol. 2010, 48, 697-703. [CrossRef] [PubMed]

33. Kersten, S. Integrated physiology and systems biology of PPARalpha. Mol. Metab. 2014, 3, $354-371$. [CrossRef] [PubMed]

34. Lillycrop, K.A.; Phillips, E.S.; Jackson, A.A.; Hanson, M.A.; Burdge, G.C. Dietary protein restriction of pregnant rats induces and folic acid supplementation prevents epigenetic modification of hepatic gene expression in the offspring. J. Nutr. 2005, 135, 1382-1386. [PubMed]

35. Zheng, J.; Xiao, X.; Zhang, Q.; Yu, M.; Xu, J.; Wang, Z. Maternal protein restriction induces early-onset glucose intolerance and alters hepatic genes expression in the peroxisome proliferator-activated receptor pathway in offspring. J. Diabetes Investig. 2015, 6, 269-279. [CrossRef] [PubMed]

36. Ringseis, R.; Gutgesell, A.; Dathe, C.; Brandsch, C.; Eder, K. Feeding oxidized fat during pregnancy up-regulates expression of PPARalpha-responsive genes in the liver of rat fetuses. Lipids Health Dis. 2007, 6, 6. [CrossRef] [PubMed]

37. Patel, R.P.; Barnes, S. Isoflavones and PPAR Signaling: A Critical Target in Cardiovascular, Metastatic, and Metabolic Disease. PPAR Res. 2010, 2010, 153252. [CrossRef] [PubMed]

38. Gudbrandsen, O.A.; Wergedahl, H.; Berge, R.K. A casein diet added isoflavone-enriched soy protein favorably affects biomarkers of steatohepatitis in obese Zucker rats. Nutrition 2009, 25, 574-580. [CrossRef] [PubMed]

39. Ronis, M.J.; Chen, Y.; Badeaux, J.; Badger, T.M. Dietary soy protein isolate attenuates metabolic syndrome in rats via effects on PPAR, LXR, and SREBP signaling. J. Nutr. 2009, 139, 1431-1438. [CrossRef] [PubMed]

40. Jia, Y.; Kim, J.H.; Nam, B.; Kim, J.; Lee, J.H.; Hwang, K.Y.; Lee, S.J. The dipeptide H-Trp-Glu-OH (WE) shows agonistic activity to peroxisome proliferator-activated protein-alpha and reduces hepatic lipid accumulation in lipid-loaded H4IIE cells. Bioorg. Med. Chem. Lett. 2014, 24, 2957-2962. [CrossRef] [PubMed]

41. Milke Garcia, M.P. Nutritional support in the treatment of chronic hepatic encephalopathy. Ann. Hepatol. 2011, 10 (Suppl. 2), S45-S49. [PubMed]

42. Bhasin, K.K.; van Nas, A.; Martin, L.J.; Davis, R.C.; Devaskar, S.U.; Lusis, A.J. Maternal low-protein diet or hypercholesterolemia reduces circulating essential amino acids and leads to intrauterine growth restriction. Diabetes 2009, 58, 559-566. [CrossRef] [PubMed]

43. Jansson, N.; Pettersson, J.; Haafiz, A.; Ericsson, A.; Palmberg, I.; Tranberg, M.; Ganapathy, V.; Powell, T.L.; Jansson, T. Down-regulation of placental transport of amino acids precedes the development of intrauterine growth restriction in rats fed a low protein diet. J. Physiol. 2006, 576, 935-946. [CrossRef] [PubMed]

44. Zheng, C.; Huang, C.; Cao, Y.; Wang, J.; dong, B. Branched-chain amino acids reverse the growth of intrauterine growth retardation rats in a malnutrition model. Asian-Aust. J. Anim. Sci. 2009, 22, 1495-1503. [CrossRef]

(C) 2017 by the authors. Licensee MDPI, Basel, Switzerland. This article is an open access article distributed under the terms and conditions of the Creative Commons Attribution (CC BY) license (http:// creativecommons.org/licenses/by/4.0/). 